\title{
A case series on large benign ovarian tumours in post-menopausal woman
}

\author{
Sujitha Sivarajan ${ }^{1, *}$, Sheila K Pillai ${ }^{2}$, Usha Vishwanath ${ }^{3}$ \\ ${ }^{1}$ Post Graduate, ${ }^{2}$ Associate Professor, ${ }^{3}$ Professor, Dept. of Obstetrics and Gynaecology, Sri Ramachandra University, Chennai,
} Tamil Nadu, India

*Corresponding Author:

Email: sujifudge@ hotmail.com

\begin{abstract}
Introduction: Space occupying large abdomino -pelvic ovarian tumours are uncommon. Such huge ovarian tumours in postmenopausal women have to be evaluated as they raise the suspicion of malignancy. The prevalence of ovarian neoplasm in postmenopausal women is $14-18 \%$ with a risk of $10-40 \%$ in the case of large complex ovarian cysts.

Objective: To study the clinical features, imaging and management of 5 post-menopausal women with large benign ovarian tumours.

Materials and Methods: A retrospective study in a tertiary care institutional hospital between December 2017- February 2018 among 5 post-menopausal women with large benign ovarian tumours.

Results: All of them presented with abdominal distension, abdominal pain and breathing difficulties. They underwent exploratory laparotomy with frozen section. Histopathology reports of all 5 showed benign ovarian tumours, the most common being serous cystadenoma.

Conclusion: The large size of the ovarian tumour warrants surgical removal of the same. This case series shows that not all extremely large tumours need to be malignant. Patients also present at a much later stage due to lack of awareness, ignorance and logistic reasons.
\end{abstract}

Keywords: Large benign ovarian tumours, Post-menopausal women.

\section{Introduction}

Ovarian cancers are the second most common gynaecological neoplasm and the seventh most common cause of cancer deaths worldwide. Menopause increases the likelihood of developing ovarian tumours. The chances of ovarian cysts in post-menopausal women being malignant is around $14 \%-18 \% .^{1}$ In case of ovarian cysts of size less than $5 \mathrm{~cm}$, risk of malignancy is only $0-1 \%$. However, in the case of large complex cysts, the risk is $10 \%-40 \%{ }^{1}$ The most common benign ovarian tumour in post-menopausal woman is serous cystadenoma. ${ }^{6,8}$

\section{Objective}

To study the clinical features, imaging and management of large abdomino-pelvic ovarian tumours in post-menopausal women.

\section{Results}

The findings of this case series are illustrated in Table 1. The mean age of presentation of symptoms was 54.6 years. Average number of years after menopause, at which the abdominal mass was diagnosed was 7.8 years. All patients had unilateral involvement of ovaries. The most common presenting complaints included abdominal distension, abdominal pain and breathing difficulties. On per abdomen examination, mass per abdomen corresponded to uterus size ranging between 28-32 weeks. On bimanual examination, uterine size was not made out and forniceal fullness due to the mass was noted. CA- 125 levels were within the normal range for 3 out of the 5

\section{Materials and Methods}

This is a case series reported from a tertiary care institutional hospital in Chennai, India between December 2017 - February 2018. It includes 5 postmenopausal women with large abdomino-pelvic tumours who presented with various symptoms. CA125 tumour marker was done and Risk Malignancy Index (RMI) was calculated for all. In view of the large size, all of them had CT imaging of abdomen and pelvis done. They subsequently underwent laparotomy with frozen section. All frozen section reports showed benign ovarian tumours, following which patients underwent total abdominal hysterectomy with removal of the other ovary. Their histopathology reports were followed up and patients were managed accordingly.

patients whereas the other 2 had elevated levels (> $35 \mathrm{U} / \mathrm{ml})$. CT imaging for 4 out of 5 cases showed features suggestive of malignancy, like multi-loculated cyst, ascites and solid components, though all of them were proved benign in the end. All the tumours were large in size ranging from 21 to $26 \mathrm{~cm}$ in greatest dimension. The various histopathology reports included borderline mucinous tumours (Fig. 1a, 2b, 3c), simple serous cyst (Fig. 1b), benign serous cystadenoma with torsion related changes (Fig. 3a, 3b) and benign seromucinous cystadenoma (Fig. 1c, 2a), with most common being benign serous cystadenoma. 
Table 1:

\begin{tabular}{|c|c|c|c|c|c|}
\hline & Mrs A & Mrs B & Mrs C & Mrs D & Mrs E \\
\hline Age (years) & 57 & 55 & 52 & 59 & 50 \\
\hline Years after menopause & 7 & 8 & 7 & 7 & 10 \\
\hline Ovaries involved & 1 & 1 & 1 & 1 & 1 \\
\hline CA- 125 (units /ml) & 17 & 9.5 & 63.8 & 29.3 & 37.2 \\
\hline USG/ CT features & $\begin{array}{l}\text { Multi-loculated } \\
\text { Thin septae }\end{array}$ & $\begin{array}{l}\text { Multi-loculated } \\
\text { Thin septae }\end{array}$ & Cystic & $\begin{array}{c}\text { Thick walled cyst } \\
\text { with calcifications } \\
\text { Thin internal septae }\end{array}$ & $\begin{array}{l}\text { Multi-loculated, Thin } \\
\text { septae, Solid } \\
\text { component, Ascites }\end{array}$ \\
\hline RMI score & 51 & 28.5 & 0 & 0 & 334.8 \\
\hline $\begin{array}{l}\text { Size of the tumour } \\
(\mathrm{cm})\end{array}$ & $25 \times 20 \times 12$ & $21.5 \times 15 \times 21$ & $17 \times 15 \times 12$ & $13 \times 26 \times 21$ & $25 \times 14.5 \times 23$ \\
\hline $\begin{array}{l}\text { Histo-pathology } \\
\text { Report }\end{array}$ & $\begin{array}{l}\text { Borderline } \\
\text { mucinous } \\
\text { Tumour }\end{array}$ & $\begin{array}{c}\text { Simple serous cyst } \\
\text { with torsion related } \\
\text { changes }\end{array}$ & $\begin{array}{l}\text { Benign serous } \\
\text { Cystadenoma }\end{array}$ & $\begin{array}{c}\text { Benign } \\
\text { Sero-mucinous } \\
\text { Cystadenoma }\end{array}$ & $\begin{array}{l}\text { Benign serous } \\
\text { cystadenoma with } \\
\text { torsion related } \\
\text { changes }\end{array}$ \\
\hline
\end{tabular}
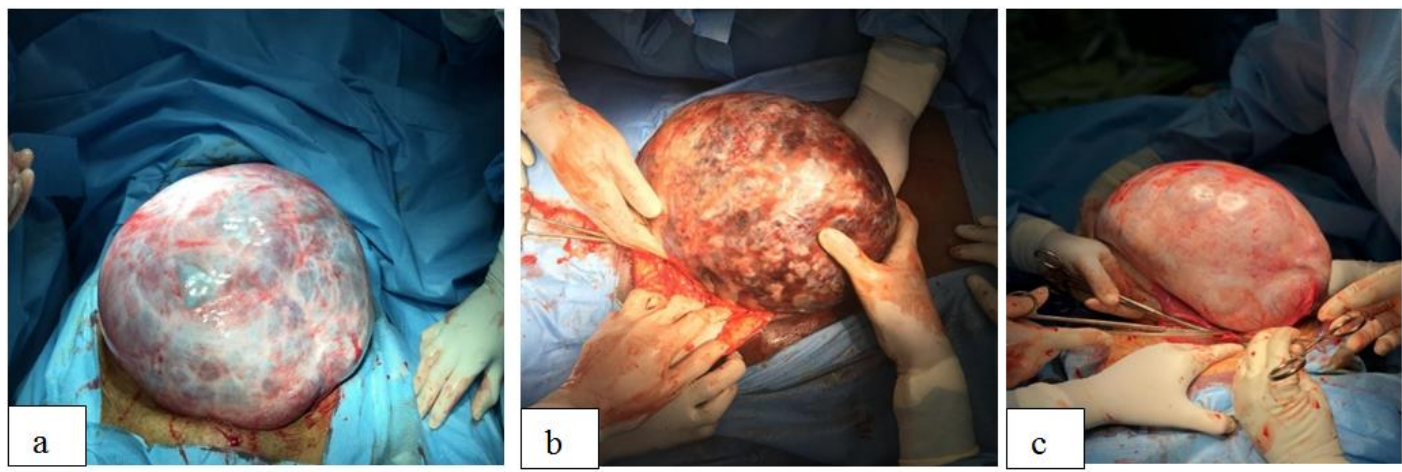

Fig. 1: Photograph showing in gross: a. Borderline mucinous tumour; b. Simple serous cyst with torsion related changes; c. Benign sero-mucinous cystadenoma
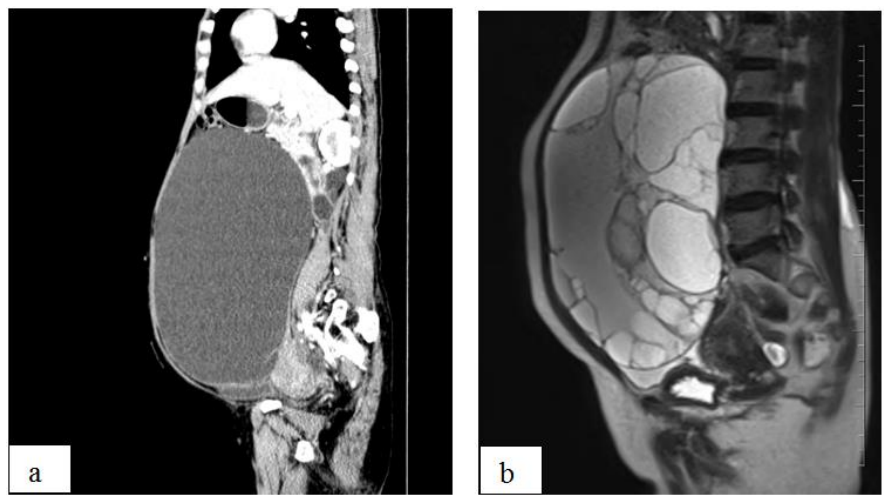

Fig. 2: MRI images of a. Benign sero-mucinous cystadenoma; b. Borderline mucinous ovarian tumour
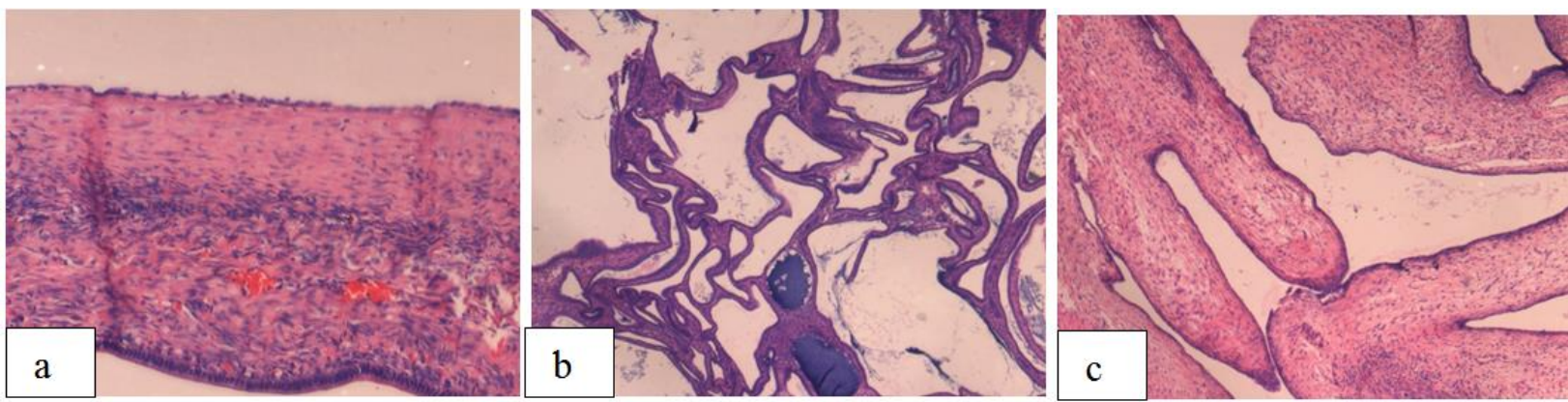

Fig. 3: Histopathology slides of a. Serous Cystadenoma; b. Benign Serous cystadenoma; c. Borderline mucinous tumour 


\section{Discussion}

The ovary is a ductless reproductive gland in which the female reproductive cells are produced. With a normal size of $3 \times 2 \times 2 \mathrm{~cm}$, it has nearly 1 million eggs at birth, which reduces to around 3 lakhs at puberty. This organ is also responsible for the secondary sexual characteristics of women by producing hormones, mainly oestrogen and progesterone. Menopause, which refers to the cessation of menstrual cycles, occurs after 45 years of age in most women. This makes them more prone to ovarian tumour due to the hormonal changes.

The incidence of ovarian tumours in postmenopausal women is commonly noted in the age group 60-80 years. ${ }^{4}$ The mean age of diagnosis in our study is 54.6 years, which is similar to a study by Jacobs et al, ${ }^{13}$ where mean age was 56 years. The incidence of ovarian tumours in modern Chennai is around 6.1 per 100000 females. $^{2}$ The 5-year survival rate for ovarian malignancy is $30-40 \%$ as they are mostly inoperable at the time of diagnosis. ${ }^{8}$

Ovarian tumours may be benign, malignant or borderline malignant. The common benign ovarian tumours are functional cysts (i.e. follicular cysts, corpus luteum cysts, theca lutein cysts) and benign neoplasms (i.e. epithelial cell tumours, germ cell tumours, stromal tumours). The commonly seen benign ovarian tumours in post-menopausal women are serous cystadenoma, mucinous cystadenoma, sero-mucinous cystadenoma. In this case series, serous cystadenoma is found to be the most common, which complies well with the studies by Mondal et $\mathrm{al}^{6}$ and Rajavigneshwari $\mathrm{N}$ et al. ${ }^{8}$ However, as per a study by Soumini $\mathrm{G}$ et $\mathrm{al},{ }^{7}$ mucinous cystadenoma was the commonest benign ovarian tumour. $30 \%$ of all ovarian tumours are serous cystadenomas. They are multi-loculated, lined by columnar or cuboidal epithelium, filled with thin clear yellowish fluid, with or without papillary projections.

These tumours may be symptomatic or asymptomatic. As the size of the tumours increase, pressure symptoms like pain abdomen, abdominal distension and breathing difficulties develop in case of large tumours extending up to the xiphi-sternum. All patients in our study had pain abdomen and abdominal distension as their primary complaints and this was in sync with a study by Yogambal et al. ${ }^{5}$ Katke RD, ${ }^{19}$ who did a study on a post-menopausal woman with a huge dermoid cyst of weight $7 \mathrm{~kg}$, also had abdominal distension as the primary complaint. So did Velanki Venkata Sujatha ${ }^{20}$ in her case report of a 66 year old South Indian post-menopausal woman with a giant ovarian serous cystadenoma weighing $23 \mathrm{~kg}$, with abdominal distension and pain as her primary complaints.

These tumours are evaluated by testing for CA 125 levels and also a transvaginal ultrasound or CT imaging in case of large abdomino-pelvic ovarian tumours. Transvaginal ultrasound imaging is known to be the single most effective way of evaluating post- menopausal ovarian tumours. ${ }^{3}$ Ultrasound imaging shows the laterality and locularity of the cyst, blood flow, presence of any papillary projections, solid areas and ascites, suggesting the possibility of either a benign or malignant ovarian tumour. In a study by DePriest et $\mathrm{al},{ }^{15} 3220$ asymptomatic post-menopausal women underwent screening by transvaginal ultrasonography between 1987-1992, which showed a decrease in the staging of ovarian cancer at detection and also the mortality arising from ovarian cancer, hence proving its efficacy as a screening tool for ovarian cancer.

A study by O'Connell et a $1^{16}$ among 56 patients presenting with pelvic masses showed that CA-125 had a negative predictive value of $100 \%$, suggesting that this test may be useful in identifying those patients with pelvic masses at a higher risk of malignancy. However, another study by Vasilev et al ${ }^{17}$ suggested that elevated serum CA 125 level by itself does not distinguish benign from malignant pelvic masses, which syncs with our study results. CA-125 levels were checked for all the patients in our study and 2 out of the 5 had values higher than 35U/ml, suggestive of malignancy. Despite these contradicting values, all proved to be benign in the end.

Risk Malignancy Index (RMI) Score is calculated as a product of CA- 125 value, Menopausal status (M) (pre-menopausal $=1$ and post-menopausal $=3$ ) and the Ultrasound score (U) (0- if no features, 1-if any one of the ultrasound features is present, 3- if 2 or more ultrasound features are present). RMI has a sensitivity of $85 \%$ and specificity of $97 \%$ with a cut-off level of 200. ${ }^{9-11}$ Here, the RMI score was in the benign range for 4 out of 5 cases which correlated with the histopathology report in the end.

Such huge ovarian masses with size more than $20 \mathrm{~cm}$ definitely warrants laparotomy with frozen section. Based on frozen section report, further steps like omental biopsies and lymph node dissection are decided. In our study, we have analysed that despite most of the patients having CA-125 levels suggesting a benign nature of the tumours, imaging studies portray the possibility of malignancy too. Hence, considering the large size of the tumours, patients were counselled about the need for laparotomy and frozen section as histopathology is the ultimate confirmatory means of arriving at a diagnosis and further management. This has a psychological impact on the patient as it makes them anxious with regards to the outcome.

While a study by Modesitt et al ${ }^{12}$ showed that the risk of malignancy of ovarian tumours of size less than $10 \mathrm{~cm}$ among women aged more than 50 years is less than $0.1 \%$, there aren't enough studies to prove the risk of malignancy in large ovarian tumours $>20 \mathrm{~cm}$ in size. Bailey et al $^{14}$ also studied that unilocular ovarian cysts $<10 \mathrm{~cm}$ in diameter in asymptomatic postmenopausal women or women $\geq 50$ years of age are associated with minimal risk for ovarian cancer. In contrast, complex ovarian cysts with wall abnormalities or solid areas are 
associated with a significant risk for malignancy. Likewise, another study by Rulin et $\mathrm{al}^{18}$ had 40 out of 63 tumours larger than $10 \mathrm{~cm}$, being malignant. However, a study by Sirishapalakodety et al ${ }^{1}$ showed that large ovarian tumours of size more than $10 \mathrm{~cm}$ need not always be malignant. Our study also shows that large ovarian tumours more than $20 \mathrm{~cm}$ in size should be thoroughly evaluated, keeping the possibility of benign nature of the tumour in mind.

\section{Conclusion}

Large benign ovarian tumours extending up to the xiphi-sternum commonly present with abdominal distension. Imaging studies showing features suggestive of malignancy like solid components, ascites and multiloculated cyst may not necessarily precede a histopathology report confirming the same. Hence, large size of the tumours need not always pose a malignant potential. They have to be evaluated thoroughly, with the main modality of management being laparotomy with frozen section, to rule out malignancy and then follow up with the histopathology report. Creating awareness among post-menopausal women about annual regular health check-up can definitely lead on to early diagnosis and accurate management at an early stage, thus improving the overall health of our population.

\section{References}

1. Sirishapalakodety S. N. R. S1, Syamala Onimi2, Usharani G3, Study of Large Benign Ovarian Neoplasms in Postmenopausal women, November Volume:6,Issue:91Page:6386-6389, JEMDS.

2. S. Shanmughapriya, G. Senthilkumar, S. Arun, B.C. Das and K. Natarajaseenivasan, 2016. Risk Factors for Epithelial Ovarian Carcinoma in India: A Case Control Study in Low-Incidence Population. International Journal of Cancer Research, 12:61-68.

3. RCOG Green-top guideline No 62, Page 4 of 14 , RCOG/BSGE Joint Guideline, November 2011, Management of Suspected Ovarian Masses in Premenopausal women.

4. Ovadia J, Goldman GA, Ovarian masses in postmenopausal women. Int J Gynaecol1992 Sep;39(1):35-9.

5. Yogambal M, Arunalatha $\mathrm{P}$, Chandramouleeswari K, Palaniappan V. Ovarian tumours-Incidence and distribution in a tertiary referral center in south India. IOSR J Dental Med Sci. 2014;13(2):74-80.

6. Mondal SK, Banyopadhayay R, Nag DR, Roychowdhury S, Mondal PK, Sinha SK. Histologic pattern, bilaterality and clinical evaluation of 957 ovarian neoplasms: a10 year study in a tertiary hospital of eastern India. J Cancer Res Ther. 2011;7(4):433-7.

7. Soumini G et al. Int J Reprod Contracept Obstet Gynecol. 2015 Aug;4(4):982-989.

8. Rajavigneshwari $\mathrm{N}$ et al., "Clinicopathological spectrum of ovarian tumours in a tertiary care hospital", Journal of evolution of Medical and Dental Sciences, vol.6, no.36, 2017, p. 2948.

9. Jacobs I., Oram D, Fairbanks J., Turner J., Frost C., Grudzinskas J. G., (1990), A risk of malignancy index incorporating CA 125, ultrasound and menopausal status for the accurate preoperative diagnosis of ovarian cancer. BJOG: An International Journal of Obstetrics \& Gynaecology, 97:922-929.

10. Tingulstad, S., Hagen, B., Skjeldestad, F. E., Onsrud, M., Kiserud, T., Halvorsen, T. and Nustad, K. (1996), Evaluation of a risk of malignancy index based on serum CA125, ultrasound findings and menopausal status in the pre-operative diagnosis of pelvic masses. BJOG: An International Journal of Obstetrics \& Gynaecology, 103:826-831.

11. Tingulstad, Solveig MD; Hagen, Bjørn MD, PhD; Skjeldestad, Finn Egil MD, PhD; Halvorsen, Tore MD, $\mathrm{PhD}$; Nustad, Kjell MD, PhD; Onsrud, Mathias MD, PhD The Risk-Of-Malignancy Index to evaluate potential Ovarian Cancers in local hospitals. ABOG: Obstetrics \& Gynecology: March 1999 - Volume 93 - Issue 3-p.448452.

12. Susan C. Modesitt, Edward J. Pavlik, Frederick R. Ueland, Paul D. DePriest, R. J. Kryscio, J. R. van Nagell. MDVOL. Risk of Malignancy in Unilocular Ovarian Cystic Tumors Less Than 10 Centimeters in Diameter, The American College of Obstetricians and Gynecologists, VOL 102, NO. 3, SEPTEMBER 2003,594-599.

13. Ian Jacobs, Ann Prys Davies, Jane Bridges, Isabel Stabile, Toby Fay, Adrian Lower, J G Grudzinskas, David Oram. Prevalence screening for ovarian cancer in postmenopausal women by CA 125 measurement and ultrasonography, BMJ Volume 30617 April 1993, 10301034.

14. C.L. Bailey, F.R. Ueland, G.L. Land, P.D. DePriest, H.H. Gallion, R.J. Kryscio, J.R. van Nagell, The Malignant Potential of Small Cystic Ovarian Tumors in Women over 50 Years of Age, Gynecologic Oncology, Volume 69, Issue 1, April 1998, Pages 3-7.

15. DePriest, P.D. et al. Ovarian Cancer Screening in Asymptomatic Postmenopausal Women, Gynecologic Oncology, Volume 51, Issue 2, 205-209.

16. O'Connell GJ, Ryan E, Murphy KJ, Prefontaine M. Predictive value of CA 125 for ovarian carcinoma in patients presenting with pelvic masses. Obstet Gynecol. 1987 Dec;70(6):930-2.

17. Vasilev SA, Schlaerth JB, Campeau J, Morrow CP, Serum CA-125 levels in preoperative evaluation of pelvic masses, Obstetrics and gynecology; 1988 May;71(5) 7516.

18. Rulin MC, Preston AL. Adnexal masses in postmenopausal women. Obstet Gynecol 1987;70(4):57881.

19. Katke RD (2016) Huge Dermoid Cyst $7 \mathrm{~kg}$ Weight in a Post-Menopausal Woman Mimicking a Malignant Ovarian Tumour: Rare Case with Review of Literature. Gen Med (Los Angel) 4:241. doi:10.4172/23275146.1000241.

20. Sujatha, Vellanki Venkata, and Sunkavalli Chinna Babu. "Giant Ovarian Serous Cystadenoma in a Postmenopausal Woman: A Case Report.” Cases Journal 2 (2009): 7875. PMC. Web. 3 Mar. 2018. 